\title{
Bow hunter syndrome in rheumatoid arthritis: illustrative case
}

\author{
Brian P. Curry, MD, ${ }^{1}$ Vijay M. Ravindra, MD, MSPH, ${ }^{2}$ Jason H. Boulter, MD, ${ }^{1}$ Chris J. Neal, MD, ${ }^{1}$ and Daniel S. Ikeda, $\mathrm{MD}^{3}$ \\ ${ }^{1}$ Department of Neurosurgery, Walter Reed National Military Medical Center, Bethesda, Maryland; ${ }^{2}$ Department of Neurosurgery, Naval Medical Center San Diego, San Diego, \\ California; and ${ }^{3}$ Department of Surgery, U.S. Naval Hospital Okinawa, Okinawa, Japan
}

\begin{abstract}
BACKGROUND Rheumatoid arthritis (RA) frequently features degeneration and instability of the cervical spine. Rarely, this degeneration manifests as symptoms of bow hunter syndrome (BHS), a dynamic cause of vertebrobasilar insufficiency.

OBSERVATIONS The authors reviewed the literature for cases of RA associated with BHS and present a case of a man with erosive RA with intermittent syncopal episodes attributable to BHS as a result of severe extrinsic left atlantooccipital vertebral artery compression from RA-associated cranial settling. A 72-year-old man with RA-associated cervical spine disease who experienced gradual, progressive functional decline was referred to a neurosurgery clinic for evaluation. He also experienced intermittent syncopal events and vertiginous symptoms with position changes and head turning. Vascular imaging demonstrated severe left vertebral artery compression between the posterior arch of C1 and the occiput as a result of RAassociated cranial settling. He underwent left $\mathrm{C} 1$ hemilaminectomy and C1-4 posterior cervical fusion with subsequent resolution of his syncope and vertiginous symptoms.
\end{abstract}

LESSONS This is an unusual case of BHS caused by cranial settling as a result of RA. RA-associated cervical spine disease may rarely present as symptoms of vascular insufficiency. Clinicians should consider the possibility, though rare, of cervical spine involvement in patients with RA experiencing symptoms consistent with vertebral basilar insufficiency.

https://thejns.org/doi/abs/10.3171/CASE21298

KEYWORDS atlantoaxial instability; bow hunter syndrome; cervical spine; positional vertebrobasilar insufficiency; rheumatoid arthritis; vertebral artery

Rheumatoid arthritis (RA) is a chronic autoimmune disease characterized by progressive inflammation and destruction of synovial joints, often with accompanying systemic complications. ${ }^{1,2}$ It affects $0.5 \%-1 \%$ of the world population and is associated with significant physical and psychosocial disability and early death. ${ }^{3,4}$ Although RA primarily affects peripheral joints, it is also the most common inflammatory disorder affecting the cervical spine, with approximately $80 \%$ of patients demonstrating some form of radiological cervical pathology within 2 years of diagnosis. ${ }^{5}$ Despite a high rate of radiographic progression, neurological deficits are rare $(2.5 \%$ of patients with prolonged course of RA). Atlantoaxial instability or an odontoid pannus may cause compressive myelopathy, ${ }^{6}$ whereas cranial settling and basilar invagination can lead to bulbar symptoms from compression of the brainstem or basilar artery. ${ }^{1,2}$
Bow hunter syndrome (BHS) is a rare neurovascular condition responsible for posterior cerebral circulation ischemia and stroke caused by dynamic mechanical compression of one or both vertebral arteries (VAs). ${ }^{7-10}$ Affected patients experience acute symptoms of vertebrobasilar insufficiency (VBI) with head movement, though the underlying etiologies of VA compression may vary. Although BHS is well described, comparatively little has been written about BHS specifically caused by RA-associated cervical spine disease, and neurovascular symptoms are not classically prominent among the presenting symptoms of RA.

Here we review the literature regarding the association between RA and BHS, and we present a case of a patient with BHS in the setting of RA-associated cervical spine disease whose symptoms rapidly resolved with posterior cervical fusion and vascular decompression.

ABBREVIATIONS BHS = bow hunter syndrome; CTA = computed tomographic angiography; DMARD = disease-modifying antirheumatic drug; RA = rheumatoid arthritis; VA = vertebral artery; VBI = vertebrobasilar insufficiency.

INCLUDE WHEN CITING Published July 19, 2021; DOI: 10.3171/CASE21298.

SUBMITTED May 17, 2021. ACCEPTED May 18, 2021.

(C) 2021 The authors, CC BY-NC-ND 4.0 (http://creativecommons.org/licenses/by-nc-nd/4.0/). 


\section{Illustrative Case}

A 72-year-old man with severe RA was referred to us for evaluation of RA-associated cervical spine disease. He had experienced several years of severe axial neck pain and gradual, progressive functional decline from myelopathy. Imaging demonstrated severe degenerative changes at the craniocervical junction with a compressive odontoid pannus and hypertrophy of the posterior atlantoaxial ligament (Fig. 1). He mostly used a wheelchair and was only able to stand briefly and ambulate short distances with a walker.

$\mathrm{He}$ also described intermittent vertiginous symptoms and syncopal events, associated primarily with transitioning to upright posture and head turning. An extensive cardiac evaluation failed to reveal an etiology for these symptoms; however, computed tomographic angiography (CTA) of the neck demonstrated severe extrinsic compression of the distal V3 segment of the dominant left VA, with the stenotic segment measuring $<1 \mathrm{~mm}$ in diameter at the site of greatest compression.
He underwent C1-4 posterior fixation with left C1 hemilaminectomy. The left VA and its investing adventitia were dissected from the sulcus arteriosus, and the site of extrinsic compression between the occiput and posterior arch of $\mathrm{C} 1$ was grossly visible. The left C1 lamina was removed, and the left VA was then followed from the $\mathrm{C} 1$ transverse foramen to the cervicomedullary dura (Fig. 2).

The patient tolerated surgery well and recovered uneventfully. Postoperative CTA demonstrated resolution of arterial compression, with a vessel diameter of approximately $5 \mathrm{~mm}$. He enjoyed steady improvement postoperatively (ambulating with a walker at 3-month follow-up) and reported complete resolution of his positional, intermittent vertiginous symptoms and syncopal events.

\section{Literature Search}

A comprehensive literature search was conducted using the PubMed electronic bibliographic database. The following
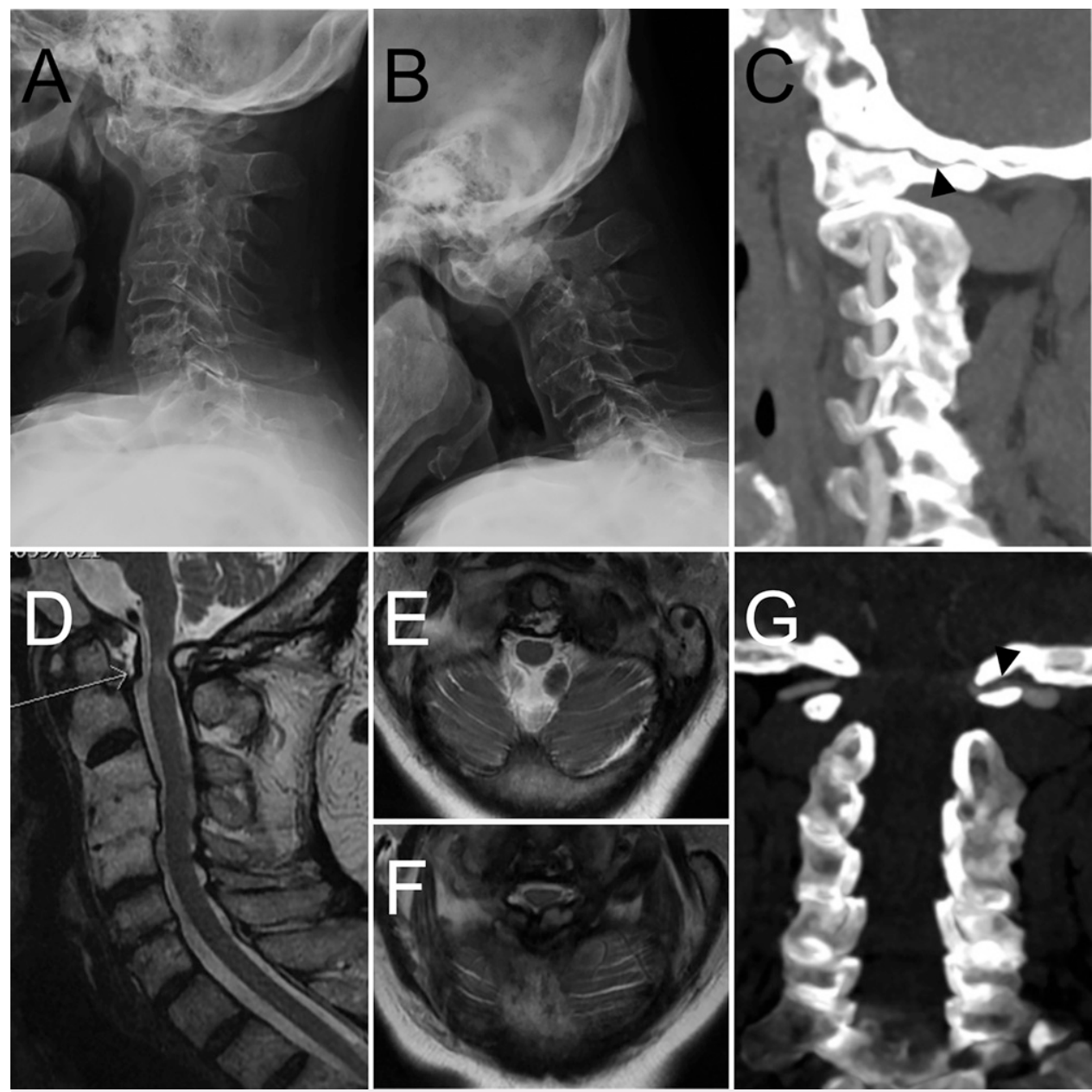

FIG. 1. Preoperative imaging showing RA-associated cervical spine disease and left VA compression. Extension $(\mathbf{A})$ and flexion $(\mathbf{B})$ radiographs showing multilevel erosive changes and widened atlantodental interval suggestive of C1-2 instability. C: Sagittal CTA showing severe compression of the left VA between the occiput and posterior arch of C1 (arrowhead). D: Sagittal T2-weighted magnetic resonance imaging (MRI) showing odontoid pannus (arrow) and exuberant posterior ligamentous hypertrophy with associated spinal cord compression and edema. E: Axial T2-weighted MRI at the craniocervical junction showing the patient's odontoid pannus and showing patency of the intradural left VA. F: Axial T2-weighted MRI showing compression of the spinal cord by the ventral odontoid pannus and dorsal hypertrophic ligament. G: Coronal CTA showing severe compression of the left VA between the skull base and the posterior arch of C1 (arrowhead). 

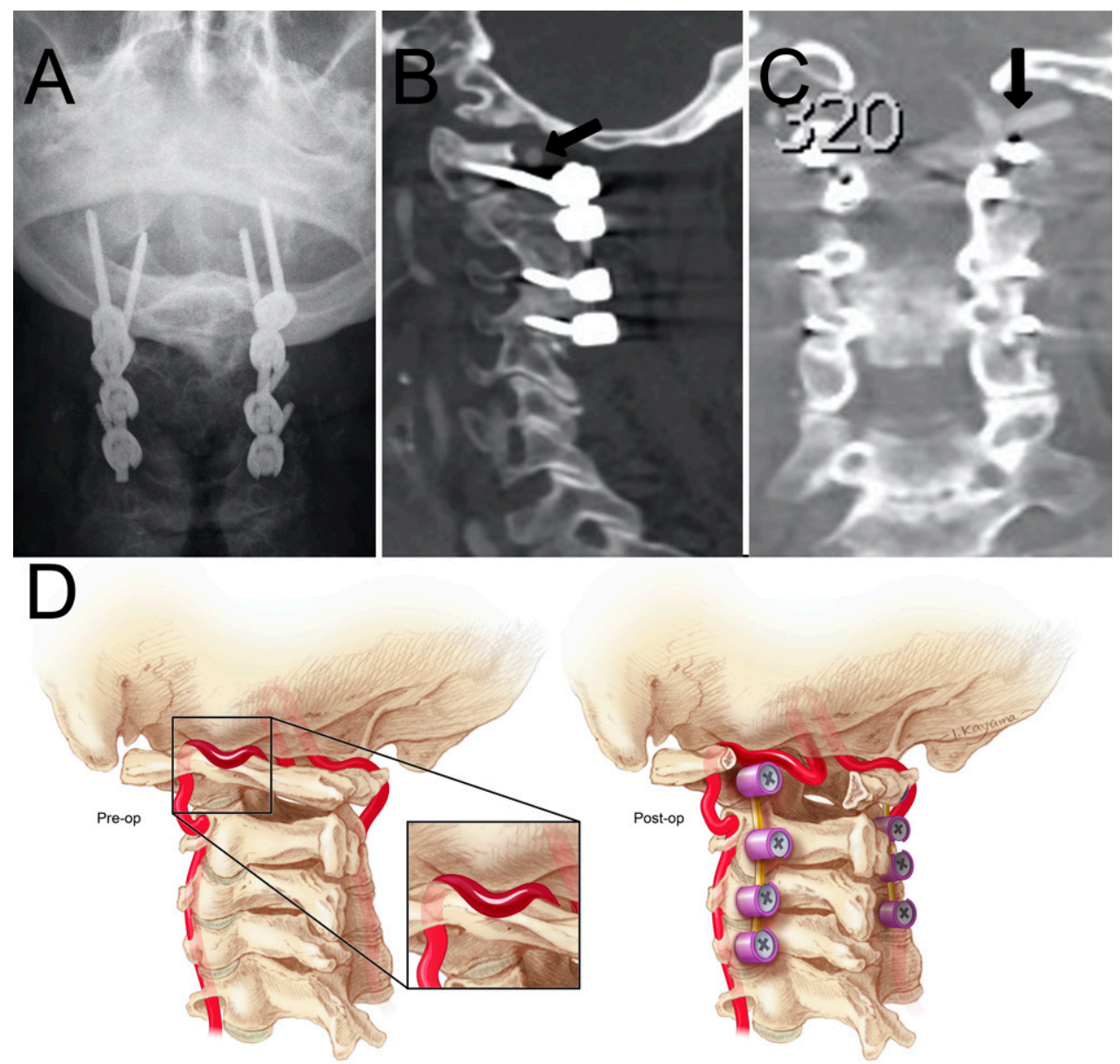

FIG. 2. Postoperative imaging and illustration. A: Anteroposterior radiograph showing C1-4 posterior segmental instrumented fusion. Sagittal (B) and coronal (C) CTA showing decompression of the left vertebral artery (black arrows). D: Preoperative illustration (right) showing compression of the left VA between the occiput and posterior arch of $\mathrm{C} 1$ (inset). Postoperative illustration (left) showing C1-4 posterior segmental instrumented fusion and decompression of the left VA.

Boolean operator terms were used: "rheumatoid" AND ("bow hunter" OR "bowhunter" OR "vertebrobasilar" OR [("occlusion" OR "compression") AND "vertebral artery"]). No date restrictions were imposed, and only English-language articles were reviewed. Included studies were case studies or clinical studies focused on describing RA as a causal etiology of BHS explicitly or those in which patients with RA demonstrated positional vertebrobasilar symptoms or presented with posterior circulation acute ischemic stroke. Studies with $\geq 1$ patient were included. Studies were excluded if they were expert opinions or studies of children or adolescents.

The initial Medline search produced 42 articles, which were assessed for relevance by screening abstracts and titles, resulting in 14 articles subjected to full review. An additional 3 case reports were identified by one of the authors (V.M.R.), ${ }^{11-13}$ resulting in a final selection of 17 articles (Table 1). Selected articles included 16 case reports of 17 patients with RA-associated $\mathrm{BHS}^{11-26}$ and 1 study assessing vertebral flow velocities based on transcranial Doppler in patients with RA, ${ }^{27}$ which yielded an additional 8 patients (Fig. 3). Including the present case, data from 26 patients were included in the analysis, in whom there were a total of 35 recorded sites of occlusion or stenosis. Data from the included articles are summarized in Table 1.

\section{Literature Review}

In the present review, the male-to-female ratio was 1:1.36, with an average age at presentation of 60.4 years (range 40-83). Information regarding the laterality of stenosis or occlusion was available in 17 patients and was left sided in 7 patients $(41.2 \%)$, right sided in 1 $(5.9 \%)$, and bilateral in $9(52.9 \%)$. The vast majority of occlusions or stenoses occurred in the V3 segment of the VA (28 [80\%]), with the remainder occurring in the V2 segment $(7[20 \%])$.

The most common presenting symptoms were syncope $(34.6 \%)$, vertigo $(26.9 \%)$, weakness/paresis (19.2\%), dizziness $(15.4 \%)$, dysarthria $(15.4 \%)$, and neck pain $(15.4 \%)$. One patient presented with a fatal stroke (Table 2). Symptoms were primarily elicited by rotation (generally contralateral) and extension. The duration of symptoms from onset to presentation was reported relatively imprecisely across the included studies but ranged from $<72$ hours to 3 years, with most patients (46\%) presenting within 3 months of symptom onset.

Nine (34.6\%) patients were known to have been prescribed diseasemodifying antirheumatic drugs (DMARDs), and $9(34.6 \%)$ were not. Data regarding DMARD use was unavailable for the remaining $7(26.9 \%)$ patients. Of patients known to be taking DMARDs, 8 patients $(88.9 \%)$ were prescribed corticosteroids as part of their regimen, either as 


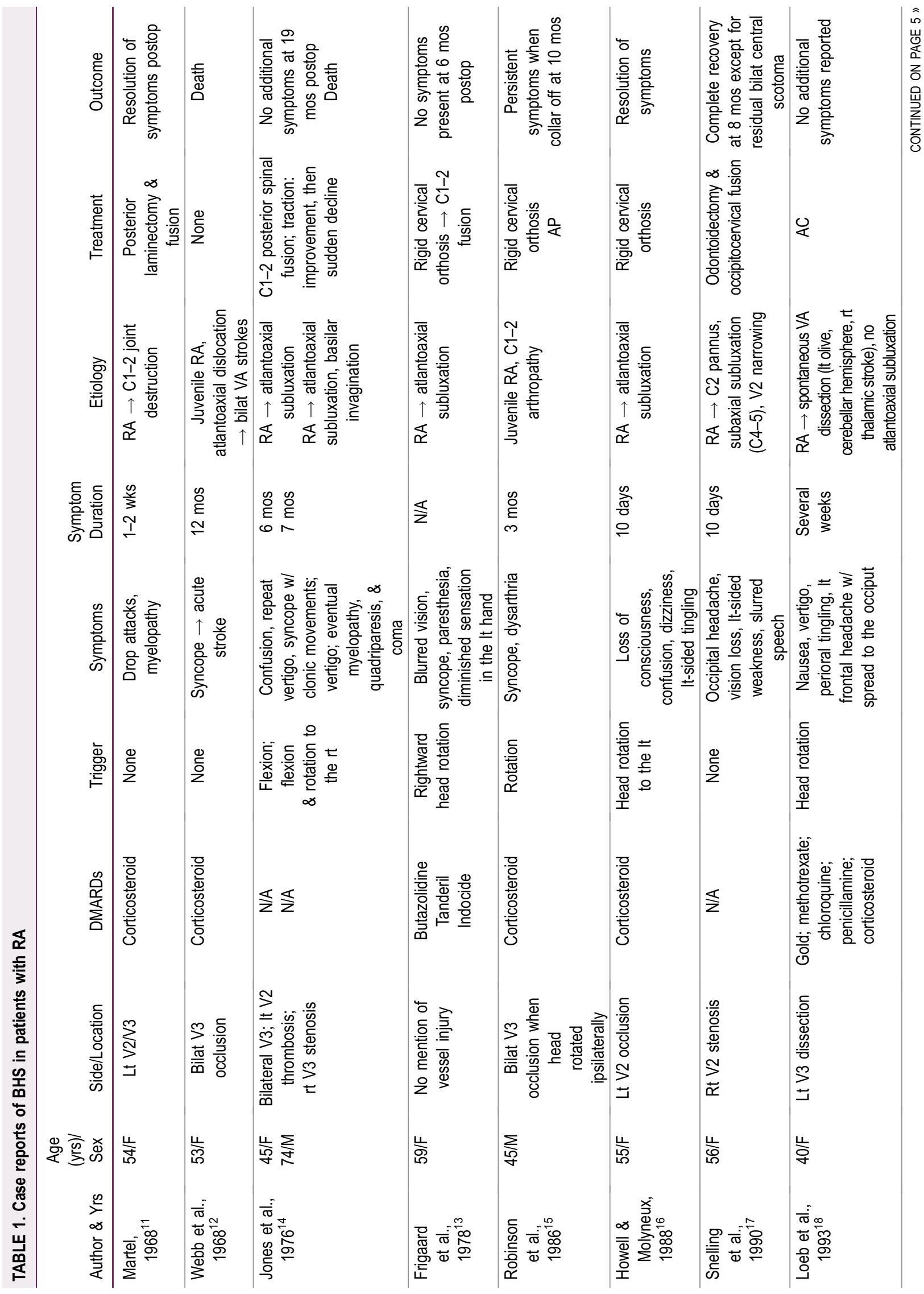




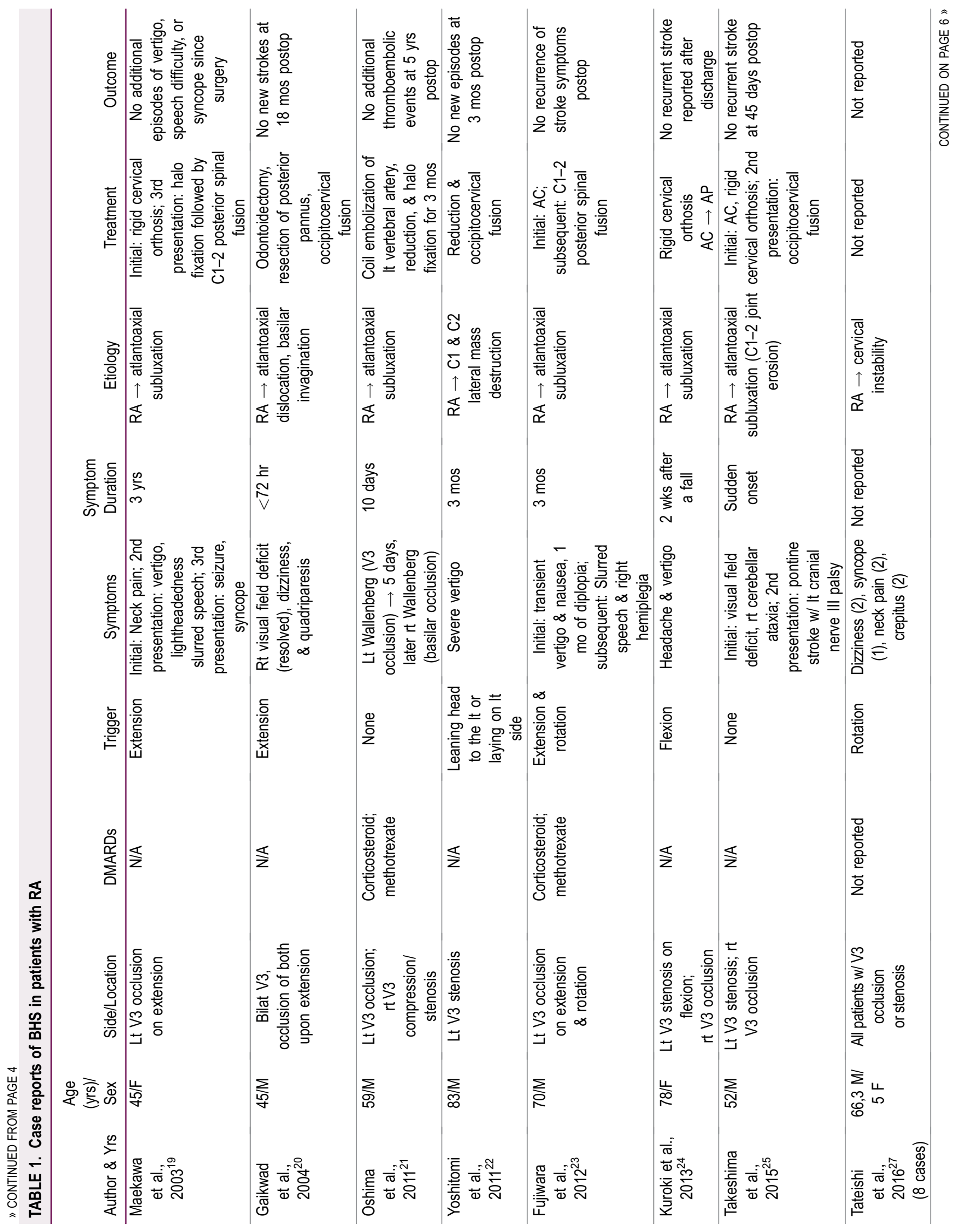


monotherapy or as part of a multidrug regimen. The second most commonly used medication was methotrexate in 3 patients (33.3\%).

Treatment information was available for 17 patients. The initial treatment was nonoperative in 10 patients $(58.8 \%): 6(35.2 \%)$ were treated with a rigid orthosis, 1 with a halo vest (5.8\%), and $2(11.8 \%)$ with anticoagulation or antiplatelet therapy alone. One patient $(5.8 \%)$ was treated with cervical traction and subsequently exhibited neurological decline and died. Eleven patients (64.7\%) underwent surgical treatment, including 4 patients initially treated nonoperatively who exhibited progressive symptoms. Thus, $40 \%$ of patients initially treated nonoperatively required subsequent surgical treatment. Of patients treated surgically, $4(40 \%)$ underwent occipitocervical fusion with or without odontoidectomy, $5(50 \%)$ underwent C1-2 fusion with or without extension to the subaxial cervical spine, and $1(10 \%)$ underwent subaxial cervical spinal fusion.

Among patients for whom follow-up information was available, symptoms were resolved in 15 at last follow-up (93.75\%), including 4 patients treated nonoperatively. One patient treated with a rigid orthosis and antiplatelet therapy experienced persistent symptoms when the collar was removed after 10 months.

\section{Discussion}

Cervical spine involvement is a common and early finding in RA, resulting in neck pain and progressive myelopathy. Rarely, RAassociated cervical spine disease may manifest as symptoms of VBI secondary to compression of the intradural VA or basilar artery by an odontoid pannus or upward herniation of the odontoid process into the foramen magnum or by attenuation of the VAs by anterior subluxation of the atlantoaxial joint. ${ }^{14,15}$ To our knowledge, this is the first incidence of BHS caused by direct compression and anchoring of the VA between the occiput and the lamina of $\mathrm{C} 1$ as a result of RA-associated cranial settling.

Descriptions of BHS associated with RA are limited primarily to case reports, and therefore data regarding the incidence of dynamic VA stenosis or occlusion in patients with RA-associated cervical spine disease are limited. Studies assessing VA abnormalities in patients with RA indicate that the incidence of VA stenosis may be as high as $19.1 \%$ and that of occlusion may be $6 \%-8.5 \%$ (compared with $2 \%$ stenosis in healthy volunteers). ${ }^{27,28}$ Notably, these data come from a population with no symptoms of $\mathrm{VBI}$, suggesting that the incidence of vascular involvement in RAassociated cervical spine disease is underrecognized. Unfortunately, data associating disease activity or duration with vascular involvement are lacking.

\section{Observations}

Our review found that the overwhelming majority of cases of BHS in RA were due to occlusion or stenosis of the V3 segment of the VA, which is consistent with the known association of RA with atlantoaxial instability. Tateishi et al. ${ }^{27}$ found that VA occlusion was associated with measures of atlantoaxial instability such as anterior and posterior atlantodens interval and Ranawat value, whereas Zenmyo et al. ${ }^{28}$ found that all cases of VA occlusion occurred in patients with lower Ranawat values, suggesting that cervical spine disease is more severe in patients with RA-associated BHS.

Because of the high morbidity and mortality burden in untreated myelopathy associated with RA, surgical decision making in RA-associated cervical spine disease often tends to be straightforward for 


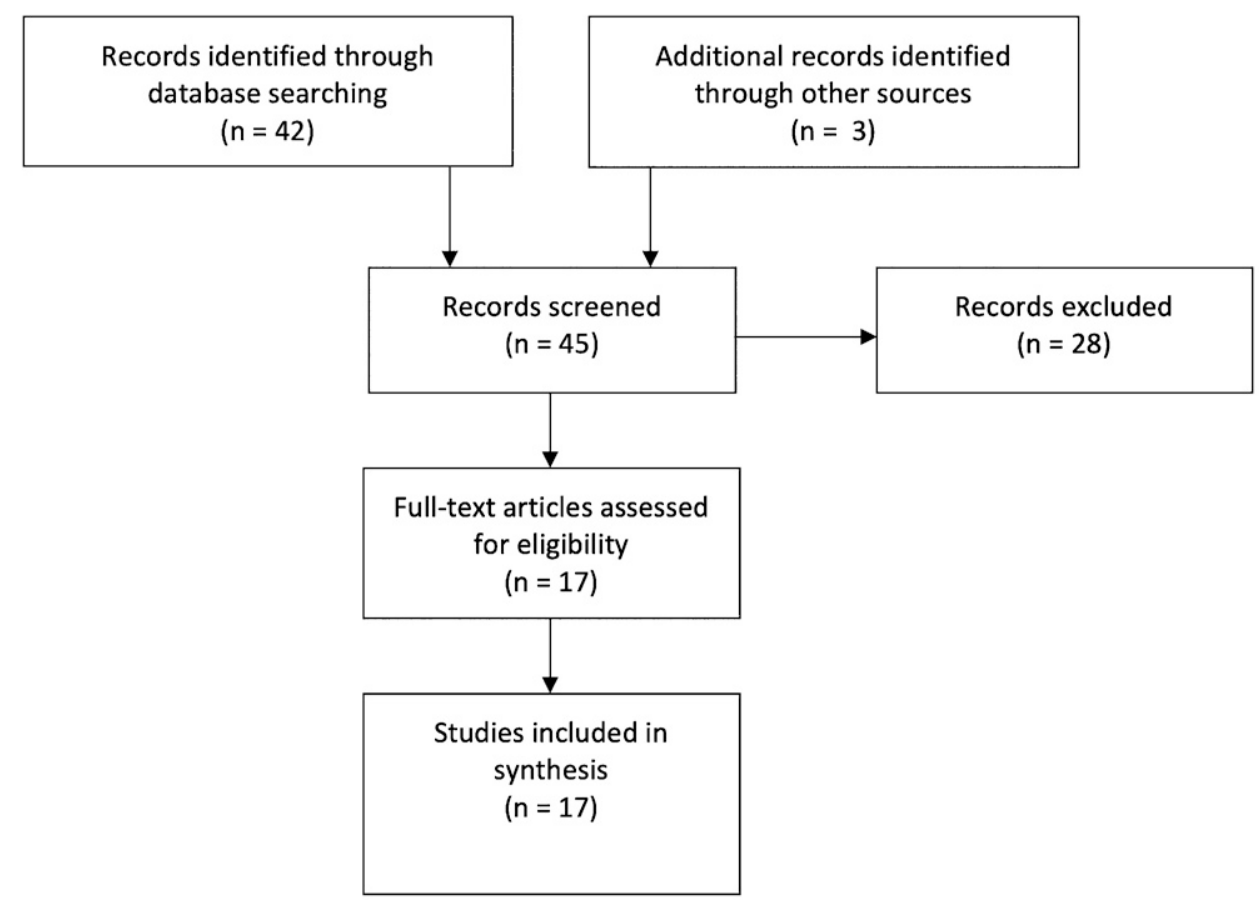

FIG. 3. Preferred Reporting Items for Systematic Reviews and Meta-Analyses flow diagram of our literature search.

TABLE 2. Presenting symptoms of BHS in RA

\begin{tabular}{lc}
\hline \multicolumn{1}{c}{ Symptoms } & Patients, no. (\%) \\
\hline Syncope & $9(34.6)$ \\
\hline Vertigo & $7(26.9)$ \\
\hline Paresis & $5(19.2)$ \\
\hline Dizziness & $4(15.4)$ \\
\hline Dysarthria & $4(15.4)$ \\
\hline Neck pain & $4(15.4)$ \\
\hline Headache & $3(11.5)$ \\
\hline Myelopathy & $3(11.5)$ \\
\hline Paresthesias & $3(11.5)$ \\
\hline Vision loss & $3(11.5)$ \\
\hline Ischemic stroke & $3(11.5)$ \\
\hline Confusion & $2(7.7)$ \\
\hline Nausea & $2(7.7)$ \\
\hline Crepitus & $2(7.7)$ \\
\hline Ataxia & $1(3.8)$ \\
\hline Blurred vision & $1(3.8)$ \\
\hline Death & $1(3.8)$ \\
\hline Diplopia & $1(3.8)$ \\
\hline Seizure & $1(3.8)$ \\
\hline Al percenta & \\
\hline
\end{tabular}

All percentages may add up to more than $100 \%$ because some patients have multiple presenting symptoms. patients with myelopathic symptoms, progressive spinal stenosis, bulbar symptoms, or cervicomedullary kinking. ${ }^{6,29}$ The natural history of VA involvement in patients with RA-associated cervical spine disease is less clear, though the relationship between measures of cervical instability and VA occlusion suggests that it may be progressive. Furthermore, given the number of patients with VA occlusion and no signs or symptoms of $\mathrm{VBI}$, assessing for clinical evidence of BHS alone may underestimate the incidence of VA stenosis or occlusion. This may be because clinical manifestations are more likely in cases of stenosis or occlusion of the dominant VA or in cases of bilateral VA involvement. Therefore, in patients with RA-associated cervical spine disease who are candidates for surgery, we recommend considering noninvasive vascular imaging to assess for VA stenosis or occlusion, particularly in patients with RA and a clinical history suggestive of VBI.

\section{Lessons}

BHS in RA is rare, though VA stenosis and occlusion are likely underreported in the literature. This review and case report highlights the need to evaluate for VA involvement when treating a patient with RA-associated cervical spine disease, and it reinforces the need for attention to a patient's history and physical examination in eliciting neurovascular symptoms. Last, it suggests that it would be reasonable to include vascular imaging as part of the preoperative evaluation, particularly for patients with RA-associated cervical spine disease and neurovascular symptomatology. 


\section{Acknowledgments}

The authors thank Ikumi Kayama, MA, for the figure published in this article. Financial support was provided by a grant from the Henry M. Jackson Foundation for the Advancement of Military Medicine to (C.J.N.).

\section{References}

1. Reiter MF, Boden SD. Inflammatory disorders of the cervical spine. Spine (Phila Pa 1976). 1998;23(24):2755-2766.

2. Nguyen HV, Ludwig SC, Silber J, et al. Rheumatoid arthritis of the cervical spine. Spine J. 2004;4(3):329-334.

3. Gabriel SE. The epidemiology of rheumatoid arthritis. Rheum Dis Clin North Am. 2001;27(2):269-281.

4. Firestein GS. Evolving concepts of rheumatoid arthritis. Nature. 2003;423(6937):356-361.

5. Krauss WE, Bledsoe JM, Clarke MJ, et al. Rheumatoid arthritis of the craniovertebral junction. Neurosurgery. 2010;66(3 suppl): 83-95.

6. Wasserman AM. Diagnosis and management of rheumatoid arthritis. Am Fam Physician. 2011;84(11):1245-1252.

7. George B, Laurian C. Impairment of vertebral artery flow caused by extrinsic lesions. Neurosurgery. 1989;24(2):206-214.

8. Fox MW, Piepgras DG, Bartleson JD. Anterolateral decompression of the atlantoaxial vertebral artery for symptomatic positional occlusion of the vertebral artery. Case report. J Neurosurg. 1995;83(4): 737-740.

9. Jost GF, Dailey AT. Bow hunter's syndrome revisited: 2 new cases and literature review of 124 cases. Neurosurg Focus. 2015;38(4):E7.

10. Schunemann V, Kim J, Dornbos D 3rd, Nimjee SM. C2-C3 anterior cervical arthrodesis in the treatment of bow hunter's syndrome: case report and review of the literature. World Neurosurg. 2018;118:284-289.

11. Martel W. Cervical spondylitis in rheumatoid disease. A comment on neurologic significance and pathogenesis. Am J Med. 1968; 44(3):441-446.

12. Webb FW, Hickman JA, Brew DS. Death from vertebral artery thrombosis in rheumatoid arthritis. BMJ. 1968;2(5604):537-538.

13. Frigaard E. Posterior atlanto-axial subluxation in rheumatoid arthritis. Scand J Rheumatol. 1978;7(2):65-68.

14. Jones MW, Kaufmann JC. Vertebrobasilar artery insufficiency in rheumatoid atlantoaxial subluxation. J Neurol Neurosurg Psychiatry. 1976;39(2):122-128.

15. Robinson BP, Seeger JF, Zak SM. Rheumatoid arthritis and positional vertebrobasilar insufficiency. Case report. J Neurosurg. 1986;65(1):111-114.

16. Howell SJL, Molyneux AJ. Vertebrobasilar insufficiency in rheumatoid atlanto-axial subluxation: a case report with angiographic demonstration of left vertebral artery occlusion. J Neurol. 1988;235(3): 189-190.

17. Snelling JP, Pickard J, Wood SK, Prouse PJ. Reversible cortical blindness as a complication of rheumatoid arthritis of the cervical spine. Br J Rheumatol. 1990;29(3):228-230.

18. Loeb M, Bookman A, Mikulis D. Rheumatoid arthritis and vertebral artery occlusion: a case report with angiographic and magnetic resonance demonstration. J Rheumatol. 1993;20(8):1402-1405.

19. Maekawa T, Sasai K, lida H, et al. Atlantoaxial arthrodesis for vertebrobasilar insufficiency due to rheumatoid arthritis: a case report. J Bone Joint Surg Am. 2003;85(4):711-714.

20. Garg A, Gaikwad SB, Kanodia A, et al. Positional occlusion/stasis of vertebral arteries in a case of cervical rheumatoid arthritis presenting with multiple posterior circulation infarcts: a case report with angiographic demonstration. Spine (Phila Pa 1976). 2004;29(15):E321-E325.
21. Oshima K, Sakaura H, Iwasaki M, et al. Repeated vertebrobasilar thromboembolism in a patient with severe upper cervical instability because of rheumatoid arthritis. Spine J. 2011;11(2):e1-e5.

22. Yoshitomi $\mathrm{H}$, Neo M, Ito $\mathrm{H}$, et al. Doppler ultrasonography and computed tomography angiography demonstrate positional occlusion of vertebral artery associated with one-sided destruction of the atlantoaxial lateral mass caused by rheumatoid arthritis: a case report. Spine (Phila Pa 1976). 2011;36(22):E1493-E1496.

23. Fujiwara H, Kaito T, Makino T, Yonenobu K. Positional occlusion of the vertebral artery in a case of rheumatoid atlantoaxial subluxation presenting with multiple cerebral and cerebellar infarction. Mod Rheumatol. 2012;22(4):605-609.

24. Kuroki T, Ueno Y, Takeda I, et al. Recurrent embolic strokes associated with vertical atlantoaxial subluxation in a patient with rheumatoid arthritis: a case report and review of literature. J Stroke Cerebrovasc Dis. 2013;22(8):e676-e681.

25. Takeshima $Y$, Matsuda R, Hironaka Y, et al. Rheumatoid arthritisinduced lateral atlantoaxial subluxation with multiple vertebrobasilar infarctions. Spine (Phila Pa 1976). 2015;40(3):E186-E189.

26. Dohzono S, Sasaoka R, Takamatsu K, Nakamura H. Bow hunter's syndrome after cervical laminoplasty in a patient with rheumatoid arthritis with bony ankylosis in the cervical spine: a case report. Mod Rheumatol Case Rep. 2020:4(1):11-15.

27. Tateishi Y, Tagami A, Baba H, et al. Duplex ultrasonographydetected positional vertebral artery occlusion in upper cervical rheumatoid arthritis. Spine (Phila Pa 1976). 2016;41(1):26-31.

28. Zenmyo M, ljiri K, Sasaki H, et al. Magnetic resonance angiography for vertebral artery evaluation in rheumatoid arthritis patients. Neurosurgery. 2010;66(6):1174-1180.

29. Peppelman WC, Kraus DR, Donaldson WF 3rd, Agarwal A. Cervical spine surgery in rheumatoid arthritis: improvement of neurologic deficit after cervical spine fusion. Spine (Phila Pa 1976). 1993; 18(16):2375-2379.

\section{Disclaimer}

The views expressed in this article are those of the authors and do not reflect the official policy of the Department of Defense or the U.S.

Government.

\section{Disclosures}

The authors report no conflict of interest concerning the materials or methods used in this study or the findings specified in this paper.

\section{Author Contributions}

Conception and design: Curry, Ravindra. Acquisition of data: Curry, Ravindra, Boulter. Analysis and interpretation of data: Curry, Boulter, Neal. Drafting the article: Curry, Ravindra, Boulter. Critically revising the article: Curry, Boulter. Reviewed submitted version of manuscript: Curry, Ravindra, Boulter, Neal. Approved the final version of the manuscript on behalf of all authors: Curry. Statistical analysis: Curry, Boulter. Administrative/technical/material support: Ravindra, Neal, Ikeda.

\section{Supplemental Information}

Previous Presentations

The case report described herein was submitted for presentation as a digital abstract for the 2021 AANS Annual Meeting.

\section{Correspondence}

Brian P. Curry: Walter Reed National Military Medical Center, Bethesda, MD. brianpcurry@gmail.com. 